\title{
Topikal Antiglokomatöz ilaç Kullanan Primer Açık Açılı Glokom Olgularında Pnömotonometre ve Tonopen ile Göz İçi Basıncı Ölçümü
}

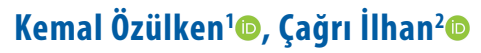

${ }^{1}$ TOBB ETÜ Tıp Fakültesi Göz Hastalıkları Anabilim Dalı, Ankara, Türkiye

${ }^{2}$ Hatay Devlet Hastanesi, Göz Hastalıkları, Hatay, Türkiye

Kemal Özülken, Dr. Öğr. Üyesi Çağrı İlhan, 0p. Dr.

Iletişim:

Dr. Öğr. Üyesi Kemal Özülken TOBB ETÜ Tıp Fakültesi Göz Hastalıkları Anabilim Dalı, Ankara, Türkiye Tel: +903122929900

E-Posta: kemalozulken@hotmail.com

Gönderilme Tarihi : 02 Haziran 2019 Revizyon Tarihi : 29 Ekim 2019 Kabul Tarihi : : 03 Kasım 2019

\section{ÖZET}

Amaç: Primer açık açlı glokomu olan ve topikal antiglokomatöz ilaç kullanan hastalarda Goldmann aplanasyon tonometrisi (GAT), pnömotonometre ve tonopen ile elde edilen göz içi basınc (GiB) ölçüm sonuçlarııı karşılaştırmak.

Gereç ve Yöntem: Randomize olmayan, olgu kontrol çalışmasında primer açık açılı glokomu olan ve topikal antiglokomatöz ilaç kullanan hastaların dosyaları geriye dönük olarak incelendi. Çalışmaya 113 hastanın sağ gözü dahil edildi. Pnömotonometre ve tonopen ile elde edilen GiB değerleri GAT ile elde edilen GiB değerleri ile istatistiksel yöntemlerle karşılaştııldı ve seriler arasındaki korelasyon araştırıldı.

Bulgular: 52'si erkek, 61'i kadın ( $p=0,638) 113$ hastanın yaş ortalaması $57,41 \pm 11,02$ yıl ( $41-82$ yıl) idi. Ortalama GiB değeri GAT ile $21,04 \pm 5,40 \mathrm{mmHg}(12-46 \mathrm{mmHg})$, pnömotonometre ile $20,19 \pm 5,61 \mathrm{mmHg}(12-48 \mathrm{mmHg})$ ve tonopen ile $17,37 \pm$ $4,99 \mathrm{mmHg}(8-44 \mathrm{mmHg})$ idi. Gerek pnömotonometre gerek tonopen ile elde edilen ortalama GiB değerleri GAT ile elde edilen ortalama GiB değerinden anlamlı olarak düşüktü (her ikisi için de $p<0,001)$. Hem pnömotonometre $(r=0,96$ ve $p<0,001)$ hem de tonopen $(r=0,83$ ve $p<0,001)$ ile elde edilen GiB ölçümleri, GAT ile elde edilen GiB ölçümleriyle anlamlı şekilde korele idi.

Sonuç: Primer açık açil glokomu olan ve topikal antiglokomatöz ilaç kullananlarda pnömotonometre ve tonopen ile ölçülen GiB, GAT ile ölçülen değerlerden daha düşük ve bu değerlerle koreledir.

Anahtar sözcükler: Glokom, primer açık açlı glokom, Goldmann aplanasyon tonometrisi, Pnömotonometre, Tonopen

INTRAOCULAR PRESSURE MEASUREMENTS WITH PNEUMOTONOMETER AND TONO-PEN IN PATIENTS USING TOPICAL ANTIGLAUCOMATOUS MEDICATION DUE TO PRIMARY OPEN-ANGLE GLAUCOMA (POAG)

\section{ABSTRACT}

Aim: To compare intraocular pressure (IOP) measurements obtained with Goldmann applanation tonometer (GAT), pneumotonometer, and Tono-pen in patients using topical antiglaucomatous medication due to primary open-angle glaucoma (POAG).

Materials and Methods: The medical documents of patients using topical antiglaucomatous medication due to primary openangle glaucoma were retrospectively investigated in this non-randomized case-control study. Only the right eyes of 113 patients were included. The IOP measurements obtained with pneumotonometer and Tono-Pen were statistically compared with the IOP measurements obtained with GAT, and the correlations between series were investigated.

Results: The mean age was $57.41 \pm 11.02$ years ( $41-82$ years) in 113 patients, 52 males and 61 females $(p=0.638)$. The mean IOP was $21.04 \pm 5.40 \mathrm{mmHg}(12-46 \mathrm{mmHg})$ with GAT, $20.19 \pm 5.61 \mathrm{mmHg}(12-48 \mathrm{mmHg})$ with pneumotonometer and $17.37 \pm 4.99 \mathrm{mmHg}$ with Tono-Pen $(8-44 \mathrm{mmHg})$. The mean IOP values obtained with both pneumotonometer and TonoPen were significantly lower than the mean IOP obtained with GAT ( $p<0.001$ for both). IOP measurements obtained with both pneumotonometer $(r=0.96$ and $p<0.001)$ and Tono-Pen $(r=0.83$ and $p<0.001)$ were significantly correlated with IOP measurements obtained with GAT.

Conclusion: IOP measurements obtained with pneumotonometer and Tono-Pen in patients using topical antiglaucomatous medication due to primary open-angle glaucoma is lower and correlated with the measurements obtained with GAT.

Keywords: Glaucoma, primary open-angle glaucoma, Goldmann applanation tonometer, pneumotonometer, Tono-Pen 
lokom, dünya genelinde en önemli körlük nedenlerinden biridir ve yüksek göz içi basıncı (GiB) en önemli değiştirilebilir risk faktörüdür $(1,2)$. GiB ölçümü glokomatöz hasta takibinde en temel basamaktır ve Goldmann aplanasyon tonometrisi (GAT), doğruluğu ve tekrarlanabilirliği bakımından, altın standart yöntem olarak kabul edilmektedir (3). Korneal yüzey üzerine uygulanan kuvvet ile belirli bir korneal alanın düzleştirilmesi ilkesine dayanan bu yöntem, merkezi korneal kalınlık, korneal elastisite, göz yaşı film tabakası veya astigmatizma gibi oküler yüzeye dair birçok farklı durumdan etkilenmektedir $(4,5)$. Bunun yanı sıra çok pratik bir yöntem değildir ve uygulanması tecrübe gerektirir. Bu bakımdan birçok farklı GiB ölçüm yöntemi, daha konforlu bir muayene ve daha güvenilir bir sonuç sağlamasının araştırııması bakımından GAT ile karşılaştırılmaktadır. Tonopen tek kullanımlık başlıkların korneaya temas etmesi yoluyla GiB'yi ölçen ve korneal yüzey anormalliklerinden daha az etkilenen bir aplanasyon tonometrisidir (6). Pnömotonometre ise korneal temas olmadan, hava akımı yoluyla korneal düzleşme ve indentasyon yaparak GiB ölçümü sağlayan bir yöntemdir (7).

Bu çalışmada, primer açık açılı glokomu olan ve topikal antiglokomatöz ilaç kullanan hasta grubunun aynı gözüne ait GAT, pnömotonometre ve tonopen ile gerçekleştirilen GiB ölçümü sonuçları arasındaki farklılığı araştırmak amaçlanmaktadır.

\section{Gereç ve Yöntem}

Söz konusu geriye dönük, randomize olmayan, olgu kontrol çalışması etik kurul onayı alınmasının ardından gerçekleştirildi ve Helsinki Deklarasyonu'na sadık kalındı.

Glokom tanısı ile en az 1 yıldır takip edilen hastaların dosyaları geriye dönük olarak tarandı. Primer açık açılı glokomu olan, topikal antiglokomatöz ilaç kullanan, 18 yaş üstü, herhangi bir göz cerrahisi geçirmemiş ve tıbbi kayıtları eksiksiz olan hastalar çalışmaya dahil edildi. Göz travması, korneal hastalık, üveit veya optik nöropati öyküsü olan, 3 $D$ ve üzeri manifest refraksiyon sferik eşdeğeri, $460 \mu$ m'den küçük ve 640 m'den büyük merkezi korneal kalınlığı olan, iris veya pupil anormalliği olan, grade 3 ve üzeri kataraktı olan hastalar çalışma dışı bırakıldı.

Çalışmaya dahil edilme kriterlerini taşıyan hastaların dosyalarında detaylı tıbbi öykülerinin bulunmasının yanı sıra en iyi düzeltilmiş görme keskinliği, biyomikroskopi ve fundoskopi muayene bulguları, korneal topografi (Pentacam, Oculus, Wetzlar, Almanya) ile ölçülmüş merkezi kornea kalınlığı, görme alanı (Humphrey Systems Field Analyzer Model II 750, Zeiss, Dublin, ABD), retina sinir lifi tabakası kalınlığı (Stratus Optical Coherence Tomography Model 3000, Zeiss, Dublin, ABD) ve kullandığı antiglokom ilaçları yer almaktaydı. Hastaların tüm muayenelerinde GiB, topikal \% 0,5 proparakain (Alcaine, Alcon, Fort Worth, TX, $A B D$ ) ile anestezi ve $\% 0,25$ flöresein ile korneal boyanma sonrası altın standart yöntem olan GAT (Haag-Streit AG, Koeniz, İsviçre) ile, deneyimli tek bir hekim (KÖ) tarafından art arda 3 defa ölçüldü ve ortalama değer kaydedildi. Illaveten hastaların son muayenelerinde, muayenenin hemen akabinde deneyimli bir teknisyen tarafından 5'er dakika aralıklarla ardışık 3'er ölçümün ortalaması alınmak suretiyle pnömotonometre (HNT-7000, Huvitz, Güney Kore) ve tonopen (Tono-Pen AVIA, Reichert, NY, ABD) ile GiB ölçümleri tekrarlanarak not alındı. Pnömotonometre ile GiB ölçümü hasta oturur pozisyonda ve cihazın kırmızı fiksasyon ışığına baktığı anda gerçekleştirildi. Tonopen ile yapılan ölçümlerde de hastadan oturur pozisyonda uzaktaki bir cismi fikse etmesi istendi. Tonopen ile yapılan GiB ölçümünde her hasta için yeni başlık kullanıldı. Cihazlar kullanma talimatları ışığında günlük kalibre edildi.

İstatistiksel araştırmaya tüm hastaların sağ gözlerinin verileri dahil edildi. İstatistiksel araştırma Statistical Package for Social Sciences (SPSS) 24,0 versiyon (IBM, Chicago, IL, $A B D$ ) ile gerçekleştirildi. Tanımlayıcı veriler ortalama \pm standart sapma (en düşük - en yüksek değerler) şeklinde verildi. Kategorik veriler ki-kare testi ile analiz edildi. Kolmogorov-Smirnov testi ile verilerin normal dağılıma uygunluğu değerlendirildi. Veriler normal dağılıma uymadığı için parametrik olmayan Wilcoxon testi kullanıldı. Pearson korelasyon analizi ile farklı yöntemlerle elde edilen sonuçların korelasyonu araştırıldı. Tüm testler için 0,05'ten küçük p değerleri anlamlı kabul edildi.

\section{Bulgular}

Çalışmaya dahil edilen Kafkas ırkından 113 glokomatöz hastanın 52'si erkek, 61'i kadındı $(p=0,638)$. Hastaların yaş ortalaması $57,41 \pm 11,02$ yıl (41 - 82 yıl) idi. Hastaların ortalama en iyi düzeltilmiş görme keskinliği değeri 0,12 \pm $0.09 \log$ MAR $(-0,1$ - 1,5 logMAR) iken santral kornea kalınlığı ortalama değeri 556,21 \pm 35,04 $\mu \mathrm{m}$ (467 - $640 \mu \mathrm{m})$ idi. Çalışmaya dahil edilen glokomatöz hastaların kullandıkları topikal antiglokomatöz ilaç sayısı ortalama 1,4 $\pm 0,3$ adet ( 1 - 3 adet) idi.

Çalışma grubunda ortalama GiB değeri GAT ile 21,04 \pm $5,40 \mathrm{mmHg}(12-46 \mathrm{mmHg})$ idi. Pnömotonometre ile elde edilen GiB ortalama değeri $20,19 \pm 5,61 \mathrm{mmHg}(12-48$ 
$\mathrm{mmHg}$ ) idi ve GAT ile elde edilen değerden anlamlı olarak düşüktü $(p<0,001)$. Tonopen ile elde edilen ortalama GiB değeri ise $17,37 \pm 4,99 \mathrm{mmHg}(8-44 \mathrm{mmHg})$ idi ve benzer şekilde bu değer de GAT ile elde edilen ortalama GiB değerinden anlamlı olarak düşüktü ( $p<0,001)$. GAT, pnömotonometre ve tonopen ile elde edilen GiB değerleri Şekil 1 'de grafik olarak verildi. Gerek pnömotonometre $(r=0,96$ ve $p<0,001)$ gerek tonopen ( $r=0,83$ ve $p<0,001)$ ile elde edilen GIB ölçümleri, GAT ile elde edilen GiB ölçümleriyle anlamlı şekilde korele idi.

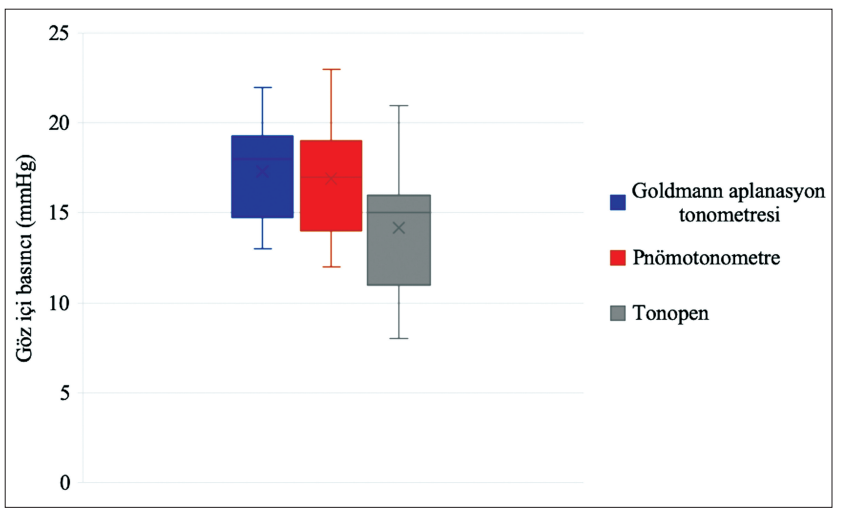

Şekil 1. Goldmann aplanasyon tonometresi, pnömotonometre ve tonopen ile elde edilen ortalama göz içi basıncı değerleri.

\section{Tartışma}

Primer açık açılı glokom hastalarında farklı yöntemlerde elde edilen GiB ölçümü sonuçlarının incelendiği bu çalışmanın sonuçlarına göre pnöomotonometre ve tonopen ile ölçülen GiB değerleri, GAT ile ölçülen değerlerden anlamlı şekilde daha düşüktür. Buna rağmen literatürde sağlıklı hasta grubunda farklı pnömotonometre cihazlarıyla yapılmış çalışmalarda, bu cihazlarla elde edilen GiB değerlerinin GAT ile elde edilen değerlerden daha yüksek olduğunu bildiren yayınlar vardır $(8,9)$. Literatür sonuçlarından farklı sonuçlar elde edilmesi, bu çalışmanın daha homojen bir hasta grubunda ve farklı model bir pnömotonometre cihazı kullanımıyla açıklanmaktadır. Bununla birlikte, birçok çalışma GAT ile ölçülen GiB değerinin $\pm 3 \mathrm{mmHg}$ içindeki, farklı yöntemle ölçülmüş GiB değerinin kabul edilebilir olduğunu bildirmektedir $(10,11)$. Bu bakımdan değerlendirildiğinde pnömotonometre ile ölçülen GiB değerinin, GAT ile ölçülen GiB değerine daha yakın ve daha korele olduğu ve $\pm 3 \mathrm{mmHg}$ aralığında bulunduğu görülmektedir. Öte yandan korneal yüzey anormalliklerinden daha az etkilendiği için GAT yöntemine önemli bir alternatif kabul edilen ve tek kullanımlık başlığı ile Avrupa'da birçok klinikte rutin uygulanan yöntem olan tonopen ile elde edilen GiB ölçüm değeri bu değerin hafifçe altındadır ve pnömotonometre ile ölçülen değerden de daha düşüktür $(12,13)$. Ülkemizden Marangoz ve ark. ise sağlıklı çalışma grubunda pnömotonometre ve tonopen ile elde ettiklerin GiB değerlerinin GAT ile elde edilen değerlere yakın olduğunu bildirmektedir (14). Benzer yöntemsel farklııkların her iki çalışmanın göreceli olarak farklı sonuçlar bildirmesinde etkili olduğu düşünülmektedir.

GiB ölçümünde sonuçlar üzerinde etkili birçok faktör vardır. Korneal biyomekanik özellikler bu faktörlerin içinde en önemlilerindendir $(15,16)$. Her ne kadar çalışmaya herhangi bir korneal hastalık öyküsü olan hastalar dahil edilmemişse ve merkezi korneal kalınlık değeri dar bir aralıktaki hastalar dahil edilmişse de korneal biyomekanik farklılıkları yok saymış olmak çalışmanın en önemli kısıtlayıcı yönüdür. Çalışmaya dahil edilen birçok hastanın birden fazla topikal antiglokomatöz ilacı kronik olarak kullanıyor olması da benzer şekilde korneal biyomekanik özellikler ve GIB ölçümü üzerine dolaylı etkilere sahip olabilecek, göz ardı edilmiş önemli bir durumdur. GlB ölçümünde uyulan protokolün tüm hastalar için sabit olması ve yöntemlerin sıralamasının değişmemesi de bir diğer önemli kısıtlılıktır çünkü pnömotonometre veya tonopen ile ölçülen GiB'ye, öncesinde uygulanan topikal anestezi ve GAT ile yapılan GiB ölçümünün herhangi bir etkisinin olup olmadığı tam olarak bilinmemektedir. Çalışmanın geriye dönük tasarlanmış olması da sonuçların güvenilirliği bakımından doğal bir kısıtlılık getirmektedir.

Primer açık açılı glokomu olan hasta grubunda farklı GiB ölçüm yöntemlerinin karşılaştııılığı bu çalışmanın en güçlü yanı, çalışma grubunun birçok bakımdan homojen olmasıdır. Psödoeksfolyasyon glokomu veya inflamatuvar glokom gibi farklı glokom çeşitlerinin dahil edilmediği bu büyük çalışma grubunda, gerek hastaların yüksek astigmatizmaya veya yoğun katarakta sahip olmaması gerek merkezi korneal kalınlıklarının çok dar bir aralıkta yer alması, sonuçların güvenilirliğini artıran durumlardır.

Sonuç olarak, primer açık açılı glokomu olan ve topikal antiglokomatöz ilaç kullanan hastalarda pnömotonometre ve tonopen ile elde edilen GIB değerleri, GAT ile elde edilen değerlerle koreledir ve GAT ile elde edilen değerlerden daha düşüktür. Bununla birlikte pnömotonometre ile elde edilen GiB ölçümleri GAT ile elde edilen GiB değerlerine daha yakın olması bakımından tonopen ile elde edilen değerlere göre daha kabul edilebilir düzeydedir. 


\section{Kaynaklar}

1. Quigley HA. Number of people with glaucoma worldwide. $\mathrm{Br} \mathrm{J}$ Ophthalmol 1996; 80: 389-93. [CrossRef]

2. Chang TC, Congdon NG, Wojciechowski R, Munoz B, Gilbert D, Chen $P$ et al. Determinants and heritability of intraocular pressure and cup-to-disc ratio in a defined older population. Ophthalmology 2005; 112: 1186-91. [CrossRef]

3. Elmallah MK, Asrani SG. New ways to measure intraocular pressure. Curr Opin Ophthalmol 2008; 19: 122-6. [CrossRef]

4. Kwon TH, Ghaboussi J, Pecknold DA, Hashash YM. Effect of cornea material stiffness on measured intraocular pressure. J Biomech. 2008:4:1707-13. [CrossRef]

5. Hamilton KE, Pye DC. Young's modulus in normal corneas and the effect on applanation tonometry. Optom Vis Sci. 2008;8:445-50. [CrossRef]

6. Chihara E. Assessment of true intraocular pressure: the gap between theory and practical data. Surv Ophthalmol 2008;53:203-18. [CrossRef]

7. Rosentreter A, Jablonski KS, Mellein AC, Gaki S, Hueber A, Dietlein TS. A new rebound tonometer for home monitoring of intraocular pressure. Graefes Arch Clin Exp Ophthalmol 2011;249:1713-9. [CrossRef]

8. Brencher $\mathrm{HL}$, Kohl P, Reinke AR, Yolton RL. Clinical comparison of air-puff and Goldmann tonometers. J Am Optom Assoc. 1991;62:395-402.

9. Schiano Lomoriello D, Lombardo M, Tranchina L, Oddone F, Serrao $S$, Ducoli P. Repeatability of intra-ocular pressure and central corneal thickness measurements provided by a non-contact method of tonometry and pachymetry. Graefes Arch Clin Exp Ophthalmol. 2011;249:429-34. [CrossRef]
10. Carbonaro F, Andrew T, Mackey DA, Spector TD, Hammond CJ. Comparison of three methods of intraocular pressure measurement and their relation to central corneal thickness. Eye (Lond). 2010;24:1165-70. [CrossRef]

11. Kim KN, Jeoung JW, Park KH, Yang MK, Kim DM. Comparison of the new rebound tonometer with Goldmann applanation tonometer in a clinical setting. Acta Ophthalmol. 2013;91:e392-e6. [CrossRef]

12. Rootman DS, Insler MS, Thompson HW, Parelman J, Poland D, Unterman SR. Accuracy and precision of the Tono-Pen in measuring intraocular pressure after keratoplasty and epikeratophakia and in scarred corneas. Arch Ophthalmol. 1988;106:1697-700. [CrossRef]

13. Bhan A, Browning AC, Shah S, Hamilton R, Dave D, Dua HS. Effect of corneal thickness on intraocular pressure measurements with the pneumotonometer, Goldmann applanation tonometer, and tonopen. Invest Ophthalmol Vis Sci. 2002;43:1389-92.

14. Marangoz D, Kohen MC, Altunsoy M, Yalvac I. Farklı tonometreler ile yapılan göz içi basıncı ölçümlerinin kornea kalınlığına göre analizi. Turkiye Klinikleri J Ophthalmol. 2017;26:193-7. [CrossRef]

15. Smedowski A, Weglarz B, Tarnawska D, Kaarniranta K, Wylegala E. Comparison of three intraocular pressure measurement methods including biomechanical properties of the cornea. Invest Ophthalmol Vis Sci. 2014;55:666-73. [CrossRef]

16. Feltgen N, Leifert, Funk J. Correlation between central corneal thickness, applanation tonometry, and direct intracameral IOP readings. Br J Ophthalmol. 2001;85:85-7. [CrossRef] 